\title{
O posicionamento dos internautas sobre a liberação dos agrotóxicos em 2019 no Brasil
}

Desde 2008, o Brasil assumiu mundialmente a primeira posição no consumo de agrotóxicos. Os debates públicos sobre as consequências deste processo têm-se intensificado e ganharam destaque a partir do ano de 2019, quando mais de 439 agrotóxicos foram liberados, com grandes repercussões na mídia brasileira. Por intermédio deste trabalho buscamos compreender as narrativas construídas pelos internautas para legitimar seu posicionamento perante a liberação de novos registros de agrotóxicos no Brasil no ano de 2019. A pesquisa partiu da reação de uma matéria do Portal de notícias G1 no Facebook. Utilizamos o método de análise de conteúdo criando categorias e subcategorias de acordo com os comentários dos internautas. Os dados obtidos revelam que $80 \%$ dos internautas se apresentam de forma desfavorável à atual liberação de agrotóxicos. No entanto, os internautas que se posicionaram de forma favorável (20\%) apoiam as narrativas do modelo agroquímico vigente, afirmando se tratar de um mal necessário. Constatamos que os internautas fazem uso de argumentos socialmente construídos como forma de legitimar seus discursos.

Palavras-chave: Risco ambiental; Agronegócio; Sustentabilidade ambiental.

\section{The position of internet users on the release of pesticides in 2019 in Brazil}

Since 2008, Brazil has taken the first position worldwide in the consumption of agrotoxic. Public debates on the consequences of this process have intensified and gained prominence from the year 2019, when more than 439 pesticides were released, with major repercussions in the Brazilian media. Through this work we seek to understand the narratives built by Internet users to legitimize their position in the face of the release of new agrotoxic records in Brazil in 2019. The research was based on the reaction of an article on the G1 News Portal on Facebook. We used the method of content analysis creating categories and subcategories according to the comments of the internet users. The data obtained reveal that $80 \%$ of the internet users are unfavorable to the current release of pesticides. However, the Internet users who positioned themselves favorably (20\%) support the narratives of the current agrochemical model, stating that it is a necessary evil. We find that Internet users make use of socially constructed arguments as a way to legitimize their discourses.

Keywords: Environmental risk; Agribusiness; Environmental sustainability

Topic: Planejamento, Gestão e Políticas Públicas Ambientais

Reviewed anonymously in the process of blind peer.
Received: 09/03/2021 Approved: 26/05/2021
Aleson da Silva Fonseca (iD

Universidade Federal do Rio Grande Norte, Brasil

http://lattes.cnpq.br/7428339911970142

http://orcid.org/0000-0002-7148-9208

fonseca.aleson@gmail.com

\section{Rafaela dos Santos Costa (iD}

Universidade Federal do Rio Grande Norte, Brasil

http://lattes.cnpq.br/3991965798614522

http://orcid.org/0000-0003-1777-6094

rafaela.costa.bio@live.com

Wagner Pereira dos Santos (iD

Universidade Federal do Rio Grande Norte, Brasil

http://lattes.cnpq.br/5597069460243330

http://orcid.org/0000-0002-7672-6049

wagnerpds5@gmail.com
Alan Kellnon Nóbrega de Carvalho (D)

Universidade Federal do Rio Grande Norte, Brasil

http://lattes.cnpq.br/1309175824657237

http://orcid.org/0000-0003-3854-5447

alankellnon@gmail.com

Raul Fernandes Dantas de Sales (it)

Universidade Federal do Rio Grande Norte, Brasil

http://lattes.cnpq.br/6331550036188115

http://orcid.org/0000-0001-6546-8956

raulsales17@gmail.com

Cimone Rozendo de Souza (ic

Universidade Federal do Rio Grande Norte, Brasil

http://lattes.cnpq.br/8227598190372706

http://orcid.org/0000-0002-4903-0839

cimone.rozendo@gmail.com
Referencing this:

FONSECA, A. S.; COSTA, R. S.; SANTOS, W. P.; CARVALHO, A. K. N. SALES, R. F. D.; SOUZA, C. R.. O posicionamento dos internautas sobre a liberação dos agrotóxicos em 2019 no Brasil. Nature and Conservation, v.14, n.2, p.174-188, 2021. DOI: http://doi.org/10.6008/CBPC2318-2881.2021.002.0016 


\section{INTRODUÇÃO}

Os agrotóxicos, em termos conceituais, também são denominados como pesticidas, praguicidas, fitossanitários e defensivos agrícolas (ALMEIDA et al., 1985). De acordo com Zechendorf (1999), a utilização desse tipo de substância contraria o conceito de desenvolvimento sustentável em função do aumento da resistência de pragas que atacam as espécies vegetais, em função da necessidade de aumentar as concentrações desses produtos, o que pode levar à extinção de predadores úteis. Adicionalmente, a ação dos agrotóxicos tem caráter difuso, podendo interferir em diferentes níveis ambientais (MELO et al., 2010; OLIVEIRA et al., 2011; GOGER et al., 2001).

O uso progressivo desses compostos começou na "Revolução Verde", resultado do aprimoramento das técnicas voltadas para alavancar a produção de alimentos, sob a justificativa de suprir as necessidades humanas em escala mundial (MACHADO, 2008). Veiga (2010) chama atenção para essa questão ao afirmar que "o crescimento da população e da produção não deve levar a humanidade a ultrapassar a capacidade de regeneração dos recursos e de absorção dos dejetos".

No entanto, os impactos ambientais dessas substâncias têm sido reportados desde 1962, quando a bióloga Rachel Carson, no livro Silent Spring (Primavera Silenciosa), documentou a poluição da água, ar e vida selvagem a partir do uso de pesticidas nocivos, como o DDT, um organoclorado persistente (MILLER et al., 2015). Além das questões ambientais, este livro também chamou a atenção sobre os possíveis riscos para a saúde humana (WALKER, 2014), e foi importante por despertar a atenção da sociedade para os problemas da poluição por agrotóxicos, culminando na regulamentação de pesticidas perigosos (MILLER et al., 2015). No entanto, não conseguiu barrar a sua utilização massiva, como principal estratégia para aumento de produtividade e elemento propulsor da "modernização" da agricultura.

Mesmo com os impactos negativos já sinalizados pela utilização de agrotóxicos, em meados de 1970 e 1980 o modelo oligárquico agroquímico, guiado pela concepção de aumento na produção de alimentos, passou a intensificar a utilização de substâncias nada sustentáveis do ponto de vista ambiental. Chamados de defensivos agrícolas em campanhas de marketing como forma de tirar o peso negativo do termo, tais substâncias são denominadas de agrotóxicos pelos críticos, revelando as contradições da racionalidade técnica-produtiva (PORTO-GONÇALVES, 2004).

Neste sentido, cabe destacar que o Brasil, desde 2008, é o maior consumidor de agrotóxicos do mundo (ABRASCO, 2015; CARVALHO et al., 2017). O modelo agrícola baseado no binômio "grande propriedade e produção de commodities" tem sido a principal razão deste aumento. A prova disso é que na primeira década deste século, o chamado agronegócio brasileiro obteve um salto vertiginoso em sua importância para a balança comercial do Brasil, mas sob forte dependência da indústria agroquímica. A demanda por produtos agrícolas em todo o mundo encaminhou o desenvolvimento de uma indústria nacional com forte emprego de recursos tecnológicos, como a mecanização da colheita, modificações genéticas e o emprego de agroquímicos (GASQUES et al., 2004).

No ano de 2010, o mercado brasileiro consumiu U\$ 7,3 bilhões desses produtos, o que totalizou $19 \%$ 
da escala mundial (ANVISA, 2019). O dossiê elaborado pela Associação Brasileira de Saúde Coletiva (ABRASCO, 2015) mostra que a comercialização de agrotóxicos cresceu em $190 \%$ nos últimos anos. Os produtos agroquímicos usados nas plantações possuem uma estratificação de mercado, sendo os herbicidas os mais vendidos e usados nas culturas, representando $45 \%$, seguido dos fungicidas com $14 \%, 12 \%$ corresponde aos inseticidas, enquanto demais produtos somam 29\% (CASSAL et al., 2014; OLIVEIRA-SILVA et al., 2001).

No entanto, os efeitos dos agrotóxicos utilizados na produção de alimentos vão variar mediante o nível de exposição a esses contaminantes (MELO et al., 2010). Como esses produtos são aplicados em lavouras, sua dispersão no ambiente pode ocorrer de diversas formas. Seja pela acumulação na biomassa vegetal, o que pode acumular em outros níveis tróficos pela ingestão de partes de vegetais contaminadas ou pela deposição no solo, onde o produto pode ser retido, lixiviado, volatilizado, fotodegradado, a dispersão pode ainda ocorrer pela degradação do produto submetido a reações químicas ou ação microbiológica. Os processos elencados podem conduzir a um contexto de contaminação de corpos hídricos pelo escoamento superficial a partir da precipitação (OLIVEIRA et al., 2011; GOGER et al., 2001). Dados da Abrasco apontam que cerca de $33,3 \%$ dos alimentos ingeridos pela população brasileira foram expostos aos agrotóxicos (CASSAL et al., 2014). A literatura tem chamado atenção também para os problemas de intoxicação por essas substâncias (PERES et al., 2005; BEDOR et al., 2009; BOCHNER, 2006; ARAÚJO et al., 2007).

Ainda que a comunidade científica venha reportando continuamente na literatura os impactos à saúde e ao ambiente ocasionados pelos agrotóxicos, no ano de 2019 foram liberados para uso 439 novas substâncias. Diante desse cenário, os governos brasileiros têm sido bastante condescendentes com o problema, em especial a partir de 2016, quando os representantes do agronegócio no Congresso Nacional passaram a orientar forte debate sobre a desregulamentação da legislação vigente. O Projeto de Lei 6299/2002, chamado pelos opositores de "PL do Veneno", e que estava praticamente parado até então, ganhou propulsão a partir de 2016, incorporando outros PLs que enfraquecem os atos normativos vigentes. Este Projeto de Lei (PL) tem como objetivo estabelecer novos regulamentos para a utilização e venda de agrotóxicos no Brasil, e propõe passar o controle da regulamentação para o Ministério da Agricultura, cabendo ressaltar que essa função é compartilhada atualmente pelo Ministério do Meio Ambiente, Ministério da Agricultura e Agência Nacional de Vigilância Sanitária (ABESSA et al., 2019).

Esse retrocesso nas políticas ambientais incentivou a expansão das fronteiras agrícolas e o uso indiscriminado dessas substâncias nocivas, com 30-35\% considerados potencialmente cancerígenos, assim, desde de o início da atual gestão do governo brasileiro, já se somam 551 pesticidas liberados (BARBOSA et al., 2021).

Em contraposição a esse processo, diversas instituições de pesquisa, sindicatos e organizações da sociedade civil (Abrasco, Instituto Nacional do Câncer, Via Campesina, Comissão Pastoral da Terra, Instituto Brasileiro de Defesa do Consumidor) têm se organizado por intermédio da Campanha Nacional Contra os Agrotóxicos e Pela Vida". A proposta da campanha é denunciar as consequências sociais e ambientais do uso indiscriminado de agrotóxicos, bem como propor a redução progressiva deste produtos por meio de uma 
legislação mais restritiva. $O$ intenso debate em torno da liberalização dos agrotóxicos tem se intensificado a partir deste contexto, envolvendo a sociedade civil em inúmeras reações nas redes sociais.

Considerando a importância destas narrativas no âmbito da sociedade da informação, neste artigo fizemos um esforço de compreender como os internautas reagem a novas liberações de agrotóxicos no Brasil. Segundo dados do IBGE (2017), 74,9\% dos domicílios brasileiros utilizam a internet, portanto, consideramos a web um ambiente de construção de sentidos por meio do compartilhamento de opiniões. Isso configura um campo de estudo importante, pois fornece elementos que nos ajudam a compreender como a sociedade vem encarando essas mudanças. Além disso, de acordo com estudos realizados por Schlegel (2009), o internauta brasileiro, de certa forma, não apresenta princípios divergentes do restante da população.

À vista disso, formulamos a seguinte questão: quais argumentos são mobilizados pelos internautas como forma de legitimar o seu posicionamento diante da crescente liberação de novos registros agrotóxicos no Brasil no ano de 2019?

A partir deste problema, este estudo teve como objetivo evidenciar o posicionamento de uma parcela da população brasileira e como esta tem enxergado a postura do atual governo mediante à liberação de novos agrotóxicos liberdos em 2019, analisando as narrativas e suas concepções sobre os riscos inerentes aos agroquímicos.

\section{MATERIAIS E MÉTODOS}

\section{Arcabouço teórico-metodológico}

O presente estudo foi realizado a partir de uma coleta de informações na rede social Facebook, a fim de analisar os comentários dos internautas sobre os novos registros de agrotóxicos liberados pelo Governo Federal, no ano de 2019. Assim, as opiniões e argumentos foram categorizados, já que se alinhavam dentro do contexto das justificativas, bem como para corroborar no processo de análise das narrativas; para isso, no processo de decodificação foi levado em consideração as unidades de significância que se aproximam à argumentação e ao posicionamento dos internautas.

Conforme sumarizado na Figura 1, este trabalho tomou como eixo estruturante a concepção de desenvolvimento proposto por Porto-Gonçalves (2004), ao afirmar que só é possível alcançá-lo por meio da igualdade; esse autor questiona ainda o atual modelo de desenvolvimento pautado na lógica da globalização neoliberal. Além disso, adotamos o conceito de formulação dos riscos ambientais, de acordo com Hannigan (1995), a fim de analisar as diferentes narrativas dos internautas e suas concepções sobre os riscos, abordando as "perspectivas sociológicas sobre o risco", "definição social do risco" e "áreas de construção de risco". Adicionalmente, foram adotadas as premissas das retóricas caracterizadas por Petersen (2015) no Dossiê da Abrasco (2015), que se baseiam em argumentos de "ocultação", "justificação" e "desqualificação". Essas proposições expressam os silogismos que fundamentam os argumentos, portanto, foram adotadas para entender o posicionamento dos internautas favoráveis aos novos registros (Figura 1).

Como este trabalho visa a analisar o posicionamento favorável ou desfavorável à liberação de novos 
registros de agrotóxicos no país ocorridos no ano de 2019, buscou-se entender como ocorre a Produção da crença em torno dessa questão; portanto, adotamos uma perspectiva de epistemologia relacional, ou seja, o modo como pensamos e agimos seria fruto das construções sociais (BOURDIEU, 2004). Neste sentido, buscamos analisar os mecanismos que levam os sujeitos a interiorizar determinados elementos vinculados à questão dos agrotóxicos, naturalizá-los e em seguida externalizá-los a partir do posicionamento. Para isso, foram adotados conceitos mobilizados por Bourdieu (2004).

\begin{tabular}{|c|c|c|c|}
\hline \multicolumn{2}{|c|}{ Formulação dos riscos ambientais (HANNIGAN, 1995) } & \multicolumn{2}{|c|}{ Retóricas (PETERSEN, 2015) } \\
\hline \multirow{3}{*}{$\begin{array}{l}\text { Perspectivas sociológicas } \\
\text { sobre risco }\end{array}$} & Percepção de risco & \multirow{3}{*}{ Ocultação } & \multirow{3}{*}{$\begin{array}{l}\text { Blindagem epistemológica } \\
\text { Blindagem jurídica } \\
\text { Limites da tolerância }\end{array}$} \\
\hline & Influência pessoal & & \\
\hline & Acidentes normais & & \\
\hline \multirow{3}{*}{ Definição social do risco } & Objeto & \multirow{3}{*}{ Justificação } & \multirow{3}{*}{$\begin{array}{l}\text { Salvação individual } \\
\text { Liberdade de escolha } \\
\text { Mal necessário }\end{array}$} \\
\hline & Prejuízo & & \\
\hline & Sistema articulado & & \\
\hline $\begin{array}{l}\text { Áreas de construção de } \\
\text { risco }\end{array}$ & $\begin{array}{l}\text { Arenas sociais } \\
\text { Papéis genéricos }\end{array}$ & Desqualificação & $\begin{array}{l}\text { Institucionalização da } \\
\text { mentira }\end{array}$ \\
\hline \multicolumn{2}{|c|}{ O desafio ambiental (PORTO-GONÇALVES, 2004) } & \multicolumn{2}{|c|}{ O círculo da crença (BOURDIEU, 2004) } \\
\hline Desenvolvimento & Igualdade & Criação & Autoridade \\
\hline \multirow[t]{2}{*}{ Globalização neoliberal } & Técnica & Circulação & $\begin{array}{l}\text { Produção } \\
\text { Relação }\end{array}$ \\
\hline & & Consagração & Reputação \\
\hline
\end{tabular}

Figura 1: Arcabouço teórico - metodológico sumarizado e empregado neste estudo.

\section{Operacionalização da pesquisa e coleta de dados}

Optamos por analisar dados provenientes do Facebook, por ser uma rede social com forte impacto coletivo e mundialmente reconhecida. Verificamos que o Facebook estava em 10 lugar no ranking brasileiro em comparação com outras redes sociais, segundo dados estimados em 08 de junho de 2019 (data de coleta dos comentários) de acordo com o website URLM. A definição do local de coleta dos dados foi baseada nas informações da Plataforma URLM, que é capaz de realizar análise estatística simplificada para websites, e desta forma, obter os dados sobre o percentual de acesso no Brasil.

Para eleger a página do Facebook que iria receber nosso estudo, optamos em definir critérios previamente, tais como, maior número de curtidas, maior número de seguidores, matéria sobre agrotóxicos publicada no ano de 2019 e que apresentasse contrapontos positivos e negativos sobre eles. A escolha desses critérios justifica-se, por acreditarmos que o resultado da nossa busca corresponderia a páginas de importantes sites de comunicação.

Foi utilizado a expressão "liberação dos agrotóxicos em 2019" na ferramenta de busca do Facebook, em seguida foi escolhido a aba "páginas" que funciona como um filtro, o que gerou a uma lista de resultados. Com isso, optamos em escolher uma página que corresponderia aos nossos critérios de seleção, onde obtivemos a página do "G1 - O Portal de Notícias da Globo", filtramos a partir da seleção da aba "publicações", e posteriormente, usamos a ferramenta de busca da página, onde inserimos novamente a 
expressão "liberação dos agrotóxicos em 2019". Observamos se o link dessa matéria corresponderia aos nossos critérios de seleção. Constatamos que a matéria se enquadra nos pontos acima mencionados ${ }^{1}$.

Para extrair os comentários do Facebook, utilizamos a plataforma Export Comments, onde foi possível gerar uma planilha Excel. Cada comentário extraído veio acompanhado com o nome de usuário que gerou o comentário, quantidade total de reações, data e horário da interação, além de especificar comentários secundários, que seriam aqueles feitos em resposta direta a um comentário anterior.

Diante disso, o presente trabalho teve como base de análise os comentários que puderam ser extraídos, considerados pela própria rede social de origem, como os de maior relevância (comentários com maior quantidade de curtidas e respostas). Adicionalmente, foi possível traçar o perfil dos internautas apenas em relação ao sexo, já que, idade, escolaridade, renda etc, são informações ausentes mediante as limitações da plataforma que utilizamos para obter o teor dos comentários.

Com o objetivo de resguardar a identidade dos perfis dos usuários, optamos em classificar os internautas com um código. Sendo assim, adotamos a expressão "usuário", seguido das iniciais do nome do perfil que teceu comentário no link da matéria, seguida do ano de coleta (exemplo fictício: Usuário BF, 2019). Na medida em que as iniciais foram se repetindo, adotamos algarismos romanos após as iniciais para referirse a outro indivíduo, de modo a possibilitar a transcrição de fragmentos representativos dos comentários, sem expor a identidade deles.

As análises foram realizadas utilizando critérios de exclusão de determinados comentários: marcação de outros usuários, utilização de elementos não textuais, tais como emoji ou figurinhas, falta de clareza na exposição, inserção de links de outras matérias, fuga da temática da matéria e repetição da opinião do mesmo usuário. Os comentários difamatórios e/ou que apresentavam trechos difamatórios também foram excluídos. Além disso, comentários de um mesmo usuário foram agrupados e classificados como comentário único.

As informações coletadas foram tratadas a partir da técnica de análise de conteúdo de Bardin (2010), que evidencia três fases analíticas: a pré-análise, a exploração do material, a análise e interpretação dos resultados. Essa técnica é importante por estratificar os dados qualitativos em categorias, nomeadas a partir da interpretação dos autores deste artigo. $O$ agrupamento é baseado em elementos que apresentam ideias semelhantes e/ou que sejam diferentes de outras categorias. Após a categorização dos comentários, as subcategorias desenvolvidas foram criadas empregando o recurso das nuvens de palavras geradas pelo software Atlas.ti 8 (ATLASTI, 2019). Além disso, para considerar as palavras mais relevantes no desenvolvimento das subcategorias, foram excluídas nas nuvens de palavras as locuções prepositivas por julgarmos sem representatividade e com o intuito de deixar em evidência o posicionamento dos internautas em relação aos argumentos mobilizados para justificar o ponto de vista.

\footnotetext{
${ }^{1}$ Matéria do portal do G1 a partir do qual os internautas teceram comentários. A notícia está intitulada como "Ritmo de liberação de agrotóxicos em 2019 é o maior já registrado".
} 


\section{RESULTADOS}

Verificamos que o link da matéria apresentava 949 comentários e 4,8 mil compartilhamentos. Observa-se ainda a quantidade, distribuição e suas respectivas reações gerais e específicas utilizando emojis: 2,2 mil curtidas; 2,1 mil raiva; 1,4 mil tristeza; 74 espantos; 55 amei e 34 risadas (dados coletados em 08 de junho de 2019). Do total de 949 comentários indicados pela própria página do G1 no Facebook, 777 foram extraídos. Esse déficit foi justificado pelo suporte da plataforma Export Comments, a qual informou que o próprio Facebook, devido ao tempo já decorrido das interações (após 7 semanas, período que iniciamos esta análise), deixou disponíveis os comentários de maior relevância em prioridade. Após os procedimentos de exclusão e aglutinação, verificamos que 329 comentários, correspondentes a 288 usuários, estavam aptos para avaliação e através da análise de conteúdo foi possível categorizar o posicionamento dos internautas, conforme a Figura 2.

Em relação ao perfil dos internautas que se posicionaram diante da matéria do G1, verificou-se que, do total de usuários, aproximadamente $53 \%$ são do sexo masculino e $47 \%$ do sexo feminino. Entre os usuários desfavoráveis (230 internautas), 58\% são do sexo masculino, contra $42 \%$ do sexo feminino. Já entre os internautas que se posicionaram de forma favorável (58 usuários), as mulheres representam $66 \%$ do total e os homens $34 \%$. Com a obtenção das nuvens de palavras (Figura 2) foi possível traçar o posicionamento dos internautas, bem como delimitar as subcategorias correspondentes ao posicionamento favorável e desfavorável.

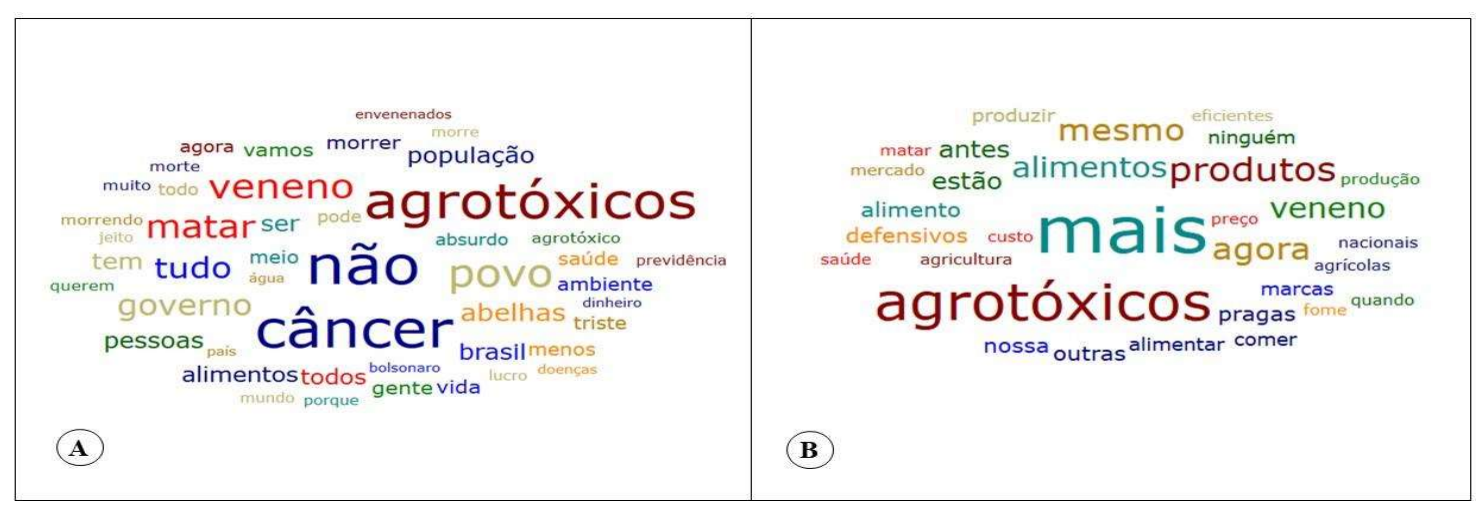

Figura 2: Nuvens de palavras oriundas dos comentários dos internautas que se posicionaram (A) de forma desfavorável, e (B) de forma favorável às recentes liberações de novos registros de agrotóxicos no Brasil ocorridas no ano de 2019.

Após a criação da nuvem de palavras, os comentários dos 230 usuários que se mostraram desfavoráveis à liberação de novos agrotóxicos se enquadraram nas seguintes subcategorias: implicações abióticas, implicações biológicas, implicações na saúde humana, implicações governamentais, mercantilização, sem justificativa e outros (Tabela 1). Consideramos como "implicações abióticas" elementos referentes à degradação de solos, ar e águas, tanto superficiais quanto subterrâneas. As "implicações no meio biológico" foram levadas em consideração quando os elementos discursivos se referiam à fauna e flora, enquanto a "saúde humana" compôs uma outra subcategoria, mediante a exposição dos eventuais malefícios à saúde das populações potencialmente afetadas. As "implicações governamentais" foram consideradas a 
partir da abordagem de aspectos de gestão da produtividade agrícola, além de eventuais posicionamentos com viés político explícito (apoio ou rejeição às ações políticas do Governo Federal). A “mercantilização" foi subcategorizada em razão da exposição argumentativa de aspectos referentes a uma alegada prioridade financeira, representada por lucros, em detrimento da qualidade ambiental e do bem-estar dos consumidores eventualmente afetados. A categoria referente à "não exposição de justificativas" foi estabelecida devido à não identificação de elementos argumentativos, onde os comentários apresentaram apenas um posicionamento lacônico, dissociado da construção de maiores debates em torno do tema proposto, sem uma reflexão da problemática abordada. Por fim, a subcategoria "outros" abrange comentários que não foram enquadrados nas subcategorias já mencionadas, seja pela insuficiência de elementos pertinentes para criação de uma subcategoria específica ou mesmo a inserção nas já existentes, conforme exemplificado na Tabela 1. Cabe ressaltar que alguns comentários apresentaram aspectos argumentativos que se coadunam em mais de uma subcategoria.

Tabela 1: Comentários representativos dos internautas para as subcategorias com posicionamento desfavorável às recentes liberações de novos registros de agrotóxicos no Brasil ocorridas no ano de 2019.

\begin{tabular}{|c|c|c|c|}
\hline Subcategorias & $\%$ & Usuário & Comentário \\
\hline Implicações abióticas & 3,8 & $\begin{array}{l}\text { JE, } \\
2019\end{array}$ & $\begin{array}{l}\text { "[...] Vocês não tem noção do impacto que os agrotóxicos químicos causam no solo, } \\
\text { nos aquíferos, em tudo [...]" }\end{array}$ \\
\hline $\begin{array}{l}\text { Implicações } \\
\text { biológicas }\end{array}$ & 7,5 & $\begin{array}{l}\text { LA, } \\
2019\end{array}$ & $\begin{array}{l}\text { "Usuário JF, 2019, estes agrotóxicos estão exterminando com as abelhas. Sem abelhas, } \\
\text { sem polinização, sem frutos e colheitas...." }\end{array}$ \\
\hline $\begin{array}{l}\text { Implicações na saúde } \\
\text { humana }\end{array}$ & 38,4 & $\begin{array}{l}\text { SRS, } \\
2019\end{array}$ & $\begin{array}{l}\text { "Claro, como não tem solução vamos continuar aumentando os pacientes dos } \\
\text { consultórios de neuropediatria, e os hospitais oncológicos! Super 'certo'. O importante } \\
\text { é colher!" }\end{array}$ \\
\hline $\begin{array}{l}\text { Implicações } \\
\text { governamentais }\end{array}$ & 21,2 & $\begin{array}{l}\text { FVS, } \\
2019\end{array}$ & $\begin{array}{l}\text { "O problema é que em } 4 \text { meses a ministra da agricultura liberou quase } 200 \text { tipos de } \\
\text { agrotóxicos" }\end{array}$ \\
\hline Mercantilização & 8,6 & $\begin{array}{l}\text { LS, } \\
2019\end{array}$ & "A ganância fala mais alto do que a razão pela qualidade da vida!" \\
\hline Sem justificativa & 6,8 & $\begin{array}{l}\text { DS, } \\
2019\end{array}$ & "Isto é péssimo!" \\
\hline Outros & 13,7 & $\begin{array}{l}\text { WH, } \\
2019\end{array}$ & "Vamos boicotar alimentos com agrotóxicos." \\
\hline
\end{tabular}

Em relação ao posicionamento dos 58 internautas favoráveis à liberação de novos agrotóxicos, os comentários foram designados nas seguintes subcategorias baseados nas retóricas da ocultação (blindagem epistemológica e limites de tolerância) e justificação (salvação individual, liberdade de escolha e mal necessário), baseado na exposição de Petersen (2015).

Tabela 2: Comentários representativos dos internautas para as subcategorias com posicionamento favorável às recentes liberações de novos registros de agrotóxicos no Brasil ocorridas no ano de 2019.

\begin{tabular}{|c|c|c|c|c|}
\hline Retórica & Subcategorias & $\%$ & Usuário & Comentário \\
\hline \multirow[t]{2}{*}{ Ocultação } & $\begin{array}{l}\text { Blindagem } \\
\text { epistemológica }\end{array}$ & 23,7 & $\begin{array}{l}\text { JMDC, } \\
2019\end{array}$ & $\begin{array}{l}\text { "Temos que saber os pormenores. São utilizados com segurança em outros } \\
\text { países? Serão fiscalizados com rigor? São seguros, enfim? Eu não creio que } \\
\text { algum governo tenha interesse em envenenar a própria população. Não por } \\
\text { ser bonzinho, mas porque pessoas doentes custam dinheiro para o sistema } \\
\text { público de saúde." }\end{array}$ \\
\hline & $\begin{array}{l}\text { Limites } \\
\text { tolerância }\end{array}$ & 8,5 & $\begin{array}{l}\text { MDGA, } \\
2019\end{array}$ & $\begin{array}{l}\text { "Me fala um caso de morte por consumo de produtos que usam } \\
\text { pesticidas...UM CASO. Não falei de pessoas que trabalham com isso e não } \\
\text { usam EPI. Quero saber de produtos...comi um tomate com pesticidas e } \\
\text { morri. Só um caso. Vamos lá." }\end{array}$ \\
\hline \multirow[t]{2}{*}{ Justificação } & $\begin{array}{l}\text { Salvação } \\
\text { individual }\end{array}$ & 8,5 & $\begin{array}{l}\text { VGDS, } \\
2019\end{array}$ & "Só plantar teu alimento no teu quintal e comer [...]" \\
\hline & $\begin{array}{l}\text { Liberdade } \\
\text { escolha }\end{array}$ & 16,9 & $\begin{array}{l}\text { KCMZ, } \\
2019\end{array}$ & "Se ele liberou o veneno ninguém é obrigado a compra é simples." \\
\hline
\end{tabular}




\begin{tabular}{llll} 
Mal necessário & 35,6 & SA, 2019 & $\begin{array}{l}\text { "Usuário WH, } 2019 \text { o que importa é alimentar a população brasileira com } \\
\text { preços acessíveis dos alimentos, uma vez que a família brasileira não tem } \\
\text { condições de manter uma alimentação orgânica, e a mesma, ainda não é } \\
\text { produzida em larga escala." }\end{array}$ \\
\hline Sem justificativa & 6,8 & $\begin{array}{l}\text { AO, } \\
2019\end{array}$ & "Nossa... comecei a consumir agrotóxicos em 2019!" \\
\hline
\end{tabular}

\section{DISCUSSÃO}

Através deste estudo foram identificadas as diferentes narrativas dos internautas sobre as liberações de novos agrotóxicos no Brasil ocorridas no ano de 2019, tomando como material de análise os comentários presentes em uma matéria da página do G1 no Facebook. A partir de uma primeira categorização, onde os usuários que comentaram na matéria foram divididos em favoráveis e desfavoráveis à liberação de agrotóxicos, verificou-se que esses internautas apresentam distintas perspectivas sobre os riscos referentes ao uso de agrotóxicos, embora o nível de rejeição tenha sido mais representativo (80\%) que o de aceitação (20\%).

Hannigan (1995) argumenta que as concepções sociais do risco se apresentam de maneiras distintas entre os atores sociais e dependem de fatores sociais, econômicos e culturais. As visões sobre o risco são moldadas a partir de percepções culturais, logo, acabam tendo múltiplos sentidos em função das oportunidades de vida terem sido diferentes para os atores envolvidos. De acordo com esse autor, a produção social do risco ambiental vai ocorrer mediante a mobilização da argumentação das autoridades científicas, que podem ser patrocinados por instituições que garantem, em certa medida, legitimidade política e social para expressar as premissas de validação dos riscos. Dessa forma, acaba por destacar de maneira articulada suas causas e consequências, que são dramatizadas por meio dos veículos de comunicação, dando notoriedade aos atores sociais afetados de forma direta e algumas vezes indiretas pela interposição do risco ambiental. Nesse contexto, ainda são mobilizados recursos simbólicos e visuais que justificam e destacam os problemas ambientais para que exista a continuidade das discussões, sobretudo garantindo o engajamento social de outros atores sociais para ajudar na disputa da construção social da pauta ambiental.

Verifica-se que o posicionamento dos internautas reflete essas percepções dúbias, sejam favoráveis ou não às liberações dos novos registros de agrotóxicos pelo governo brasileiro. Isso reflete o resultado das estruturas sociais que levam os indivíduos a ter diferentes disposições sobre o tema, desta forma, estabelecendo agrupamentos que refletem os diversos posicionamentos observados, fazendo uso de retóricas (Tabelas 1 e 2) e legitimando a aceitação ou a recusa a esses novos produtos que serão comercializados. Ainda nesta perspectiva sociológica, Hannigan (1995) afirma que o risco é constituído a partir de um apelo imagético, embora não sejam todos os atores sociais que conseguiram aceitar que o risco carrega de fato algum efeito negativo, tendo em vista que as condições de vida podem eventualmente serem diferentes. Isso fica evidente nos argumentos dos internautas que se posicionaram favoráveis aos novos registros, fazendo uso de elementos especulativos e quantitativos que ocultam os graves problemas decorrentes de agrotóxicos.

Em contrapartida, alguns comentários que se posicionaram de forma desfavorável associam a ideia 
de acidentes normais ou inevitabilidade oriunda da tecnologia, conforme identificado na obra de Hannigan (1995). No presente estudo, toda a mobilização em torno da técnica (agrotóxicos), advinda de alguns comentários desfavoráveis à liberação de mais agrotóxicos, apresenta capacidade de provocar efeitos deletérios tanto no que diz respeito aos impactos na saúde como implicações ambientais, como demonstramos anteriormente nas subcategorias identificadas a partir deste estudo, bem como, as evidências nas implicações de saúde descritas no Dossiê da Abrasco descritas no Dossiê da Abrasco (CARNEIRO et al., 2015).

Além disso, cabe ressaltar que se deve considerar o contexto social em que as preocupações humanas se desenvolvem, pois as influências primárias e secundárias, que operam na formação do indivíduo, como afirmado por Hannigan (1995), influenciam como filtros na difusão das informações e são esses elementos que moldam as percepções dos sujeitos. Essas ideias de influências primárias e secundárias propostas por Hannigan (1995) se coadunam com o conceito de habitus desenvolvido por Bourdieu (2004), no qual a internalização, naturalização e externalização de valores e princípios os conduzem a acreditar que algo é ou não legítimo.

Nesse contexto, o círculo da crença sobre os agrotóxicos estão ligados às distintas estratégias de poder que envolvem uma diversidade de atores sociais. Portanto, há o acionamento de elementos, como a figura da autoridade que utiliza mecanismos discursivos que visam persuadir o receptor da mensagem. Com isso, alegam que determinado produto (que no caso deste estudo são as novas substâncias liberadas) apresenta um sentido, que pode ser benéfico ou não. A eficácia na construção da verdade vai depender de quem aciona os argumentos e qual o seu objetivo (BOURDIEU, 2004) e dos distintos contextos, podendo inclusive, colocar seus interesses acima do bem-estar humano e ambiental.

O papel da autoridade, como foi demonstrado por Bourdieu (2004), tem revelado uma estratégia linguística-ideológica (PORTO-GONÇALVES, 2004). Uma vez que as empresas agroquímicas utilizam campanhas publicitárias com o intuito de disseminar a utilização da palavra "defensivo", projetam a substituição do seu significado por um outro essencialmente positivo para o contexto defendido. Tal estratégia busca modificar a percepção do público, onde ao invés de ser visto como um composto danoso para o ambiente, acaba por ocultar a sua natureza biocida (CARSON, 2002), ou seja, revela o seu sentido ideológico pautado na defesa da lógica da globalização neoliberal. $\mathrm{O}$ autor complementa argumentando que o combate às pragas se revela como uma condição de dominação da natureza (PORTO-GONÇALVES, 2004). Nessa perspectiva, tal discurso é verificado nos resultados apresentados, de modo que a utilização do termo "defensivos" é exposta na nuvem de palavras na categoria de comentários favoráveis.

Convém ressaltar que o produto (agrotóxicos) não apresenta neutralidade e sua construção social revela os múltiplos sentidos que podem ser acionados como ferramenta de convencimento. Para isso, a disputa de poder faz uso de diferentes relações como forma de garantir a apropriação desse sentido que quer ser evidenciado, chegando à última etapa desse círculo, a consagração, em que a reputação e autoridade são de fato consolidadas pelos atores sociais (BOURDIEU, 2004). Este autor destaca ainda o poder da convicção no círculo da crença, revelando as características do campo da produção e do consumo. Uma 
vez que as autoridades fazem uso da imposição ideológica através de estratégias atuais de marketing, se estabelece o intuito de qualificar um produto durante as etapas de divulgação, acunhando slogans do tipo, "se é Bayer, é bom" ou "agro é tech, agro é pop, agro é tudo". Nessa perspectiva, em decorrência das transformações sociais e políticas que o Brasil tem passado nos últimos anos, observam-se tensões em torno da construção de narrativas que ocultam os riscos associados ao uso de agrotóxicos. Para tal, as estratégias empregadas vão desde esconder as diferenças entre o agronegócio e a agricultura familiar, até usar suas pautas e ideias para "pegar carona", tendo em vista a imagem de legítima confiança que a base agroecológica conquistou por meio da opinião pública (MOURA et al., 2020).

Essas estratégias contribuem para a construção da convicção a partir de um apelo imagético, por parte das empresas agroquímicas. Na medida em que existe uma polarização em torno de um dado produto ou conceito representado por este, que neste caso está representada pelo antagonismo dos comentários analisados, de modo que os internautas se posicionaram de forma favorável e desfavorável ao uso e liberação de novos registros de agrotóxicos, esses mecanismos persuasivos são acionados como forma de garantir a convicção por parte dos atores sociais, portanto, o que configura-se como uma disputa de poder (BOURDIEU, 2004). Esta disputa ideológica em torno da percepção de riscos ambientais ficou evidente nos comentários analisados, demonstrando que de fato à argumentação dos internautas está de acordo com a perspectiva relacional de Bourdieu (2004). Em adição, os argumentos expostos pelos internautas também se relacionam com a perspectiva sociológica do risco descrita por Hannigan (1995), as retóricas reportadas por Petersen (2015) e em certa medida aos argumentos explicitados por Porto-Gonçalves (2004) quando se trata do uso e aceitação da técnica e confiança na ciência.

No decorrer desse processo de criação de narrativas para legitimar as atividades insustentáveis do agronegócio brasileiro, foi organizado o movimento "Sou Agro", em 2011, com o claro propósito de auxiliar na construção de uma imagem positiva desse segmento (MOURA et al., 2020). Isso pode explicar, em certa medida, o porquê de uma parcela dos internautas aceitar e tolerar os riscos atrelados ao uso dos agrotóxicos, como forma de manter a produção de alimentos no país. Sabe-se, portanto, que esse movimento tem galgado êxito, com apoio popular de grupos mais conservadores.

Em contrapartida, com o advento da publicação do Dossiê da Abrasco (2015), muitos estudos reportam os problemas ambientais e de saúde pública atrelados a essas práticas insustentáveis do agronegócio. É nítido as tensões entre o segmento da agricultura familiar e o agronegócio, de modo que muitos palcos têm sido utilizados para disseminação das contraposições de ambos os setores (MOURA et al., 2020).

Diante do exposto, Bourdieu (2004) afirma que nesses locais ocorrem disputas de poder para construção de narrativas e "produções de verdades". Hannigan (1995) chama esses espaços de arenas sociais, de modo que ele explica que se trata de um local com o propósito de influenciar o exercício político. Tendo em vista a abordagem de Hannigan (1995) ao se debruçar sobre essas disputas, o palco que utilizamos nesta análise foi a rede social Facebook, um espaço aparentemente democrático no sentido de cada indivíduo apresentar suas opiniões sobre um determinado assunto. No entanto, como partimos de uma 
perspectiva relacional (BOURDIEU, 2004), alguns elementos que compõem o posicionamento dos internautas são frutos de construções sociais, em que existe a externalização dos sentidos em torno dos agrotóxicos, a partir de elementos que são formulados por grupos diferentes, logo, isso é colocado à população como forma de convencimento.

Por outro lado, Hannigan (1995) chama esses grupos de comunidades de operadores, e seu papel é alimentar os outros operadores, ou seja, eles são capazes de fornecer a argumentação que embasa o posicionamento dos internautas. À vista disso, deve-se considerar que os comentários dos internautas contêm elementos presentes nos seis papéis genéricos que Hannigan (1995) postula (portadores de risco; Defensores dos portadores de risco; Geradores de risco; Ajudantes; Árbitros de risco e Informadores de risco). Nesta análise, é possível identificar que os portadores de risco são as pessoas supostamente expostas aos efeitos dos agrotóxicos, incluindo os internautas; os defensores dos portadores de risco neste caso, poderiam citar os autores do Dossiê da ABRASCO, que se apresentam desfavoráveis em função dos riscos e/ou sua imprevisibilidade; os geradores de riscos são as empresas agroquímicas; os investigadores do risco, também conhecidos como ajudantes, podem destacar o papel dos cientistas na definição dos níveis ditos aceitáveis de exposição aos agrotóxicos, embora esses achados podem ser contestados por outros pesquisadores; $o$ árbitro do risco, no caso brasileiro seria os órgãos públicos, tais como, o congresso, a própria ANVISA e dentre outros; já os informadores do risco estão relacionados aos meios de comunicação (HANNIGAN, 1995; CARVALHO et al., 2017; PORTO-GONÇALVES, 2004).

Ainda no que diz respeito ao risco, salienta-se que a definição social desse conceito descrita por Hannigan (1995) apresenta alguns elementos, sendo eles: o objeto, o prejuízo e o sistema articulado. O objeto é a origem primária de um risco com algum prejuízo identificado; portanto, observamos nas falas dos internautas que se posicionaram de forma desfavorável que os agrotóxicos têm efeitos negativos sobre diferentes aspectos socioambientais (Tabela 1 ) e o sistema articulado a combinação do objeto e o dano (prejuízo) (HANNIGAN, 1995). Tal combinação verificamos no Dossiê da Abrasco sob a perspectiva das retóricas de Petersen (2015), à medida que reúnem dados e informações com o intuito de alertar a população sobre os efeitos da utilização dos agrotóxicos e questionar a ciência quanto à validade de aplicação desta técnica (CARVALHO et al., 2017).

Com relação à determinação de um risco, podem ser associados a vários objetos. Além disso, mesmo que identificado um risco com consequências imediatas, leva-se um longo período para que se reúnam informações para que tal risco seja reconhecido publicamente (HANNIGAN, 1995). Esta constatação é evidenciada neste artigo, principalmente, associada aos comentários de retórica da ocultação, como por exemplo o comentário feito pelo Usuário DF, 2019 (Tabela 2).

Partindo dessa exposição, o círculo da crença e as questões referentes ao risco em torno do nível de aceitação dos novos registros de agrotóxicos revelam o que Porto-Gonçalves (2004) chama de intencionalidade da técnica. Para o autor, a técnica é organizada por um sistema social que dá a ela um caráter dúbio, portanto, a maneira como é usada revela um posicionamento político, que nesse caso, tem se mostrado hegemônico, no sentido de buscar dominar a natureza a favor da lógica da globalização neoliberal. 
Este aspecto fica evidente no raciocínio dos internautas que se posicionaram favoráveis ao emprego da retórica da ocultação uma vez que blindam epistemologicamente o problema, criando a falsa concepção de que o risco pode ser evitado. Já a retórica da justificação também verificada neste estudo se relaciona com os argumentos dos internautas, em que a utilização dos agrotóxicos é colocada como um "mal necessário", principalmente atrelado ao aumento da produtividade; portanto, é justificável como forma de sanar a demanda alimentar (PETERSEN, 2015).

Esse raciocínio apresenta similaridade com Porto-Gonçalves (2004) ao expor que o emprego da técnica, nesse caso a utilização de agrotóxicos, que é capaz de solucionar a demanda por alimentos e consequentemente, é usado como método de impulsionar o aumento das áreas agrícolas para obter resultados expressivos. Neste sentido, para Porto-Gonçalves (2004), a utilização dos agrotóxicos seria resultado da globalização neoliberal que fundamenta a concepção de desenvolvimento, ou seja, erroneamente, o desenvolvimento é entendido como sinônimo de dominação da natureza por meio da técnica. Isso descaracteriza a concepção de igualdade, que é o centro dos argumentos de Porto-Gonçalves (2004).

Essa ideia de globalização neoliberal exemplificada por Porto-Gonçalves (2004) estruturou a visão dicotômica de modernidade versus colonialidade, onde o primeiro é entendido como progressistas: satisfatório e hegemônico, detentor do poder e da técnica, que corresponde ao conhecimento científico e suas ferramentas para dominação da natureza. Por outro lado, tudo aquilo que não corresponde a esses elementos é chamado de colonial, ou seja, atrasado, embora ele afirme que um não consegue existir separado do outro.

Segundo Porto-Gonçalves (2004), existem dois pilares que estruturam o modelo agrário-agrícola vigente: o primeiro é a valorização exacerbada da ciência e da técnica; o segundo é o aumento da extensão de terras cultiváveis. Essas ideias hegemônicas ficaram evidentes em alguns comentários que se posicionaram de forma favorável às atuais liberações de novos registros de agrotóxicos nas subcategorias mal necessário, limites de tolerância e blindagem epistemológica. Tal posicionamento indica que a argumentação está alicerçada na lógica questionada por Porto-Gonçalves (2004) ao usar a técnica para dominar a natureza, revelando um abismo na relação homem-natureza, beneficiando grupos empresariais e alimentando os processos que levam à desigualdade.

\section{CONCLUSÕES}

Neste artigo constatamos uma dualidade em termos do posicionamento dos internautas sobre a liberação de novos registros de agrotóxicos no Brasil, legitimando seu uso a partir da mobilização das retóricas da ocultação e justificação, reiterando que o uso dos agrotóxicos é necessário num contexto de demandas alimentares crescentes. Em contrapartida, os internautas que se posicionaram desfavoráveis apresentaram argumentos que expressam os riscos difusos, seja afetando a saúde humana, implicações biológicas, abióticas, governamentais, mercantilização, ficando evidente os mais diversos prejuízos que essas substâncias podem trazer para o meio ambiente. Cabe ainda ressaltar que a categoria desfavorável foi mais 
expressiva, em detrimento ao posicionamento favorável às atuais liberações.

Apesar desta constatação, no tocante aos comentários favoráveis, estes trazem à tona a ideia da desigualdade pelo modelo agrário-agroquímico vigente, questionada pela perspectiva dos autores articulados neste trabalho, tendo em vista que a base para atingir o desenvolvimento respaldada nas ideias de igualdade, sobretudo, no respeito às questões ambientais.

Levando em consideração a perspectiva sociológica, verificamos que os comentários fazem uso de argumentos socialmente construídos, seguindo o modelo do relacional, onde as convicções foram edificadas dentro do círculo da crença, com articulação de elementos imagéticos que também contribuem como forma de legitimar o discurso dos internautas, reforçando ou enfraquecendo as exigências impostas pelos internautas.

\section{REFERÊNCIAS}

ABESSA, D.; FAMÁ, A.; BURUAEM, L.. The systematic dismantling of Brazilian environmental laws risks losses on all fronts. Nature Ecology \& Evolution, v.3, n.4, p.510-511, 2019. DOI: http://doi.org/10.1038/s41559-019-0855-9

ALMEIDA, W.; FIÚRA, J.; MGALHÃES, C. M.; JUNGER, C. M.. Agrotóxicos. Cadernos Saúde pública, v.1, n.2, p.220-249, 1985. DOI: http://doi.org/10.1590/S0102311X1985000200008

ANVISA. Ministério da Saúde. Agrotóxicos. Brasília: Ministério da Saúde, 2019.

ARAÚJO, A. J. D.; LIMA, J. S. D.; MOREIRA, J. C.; JACOB, S. D. C.; SOARES, M. D. O.; MONTEIRO, M. C. M.; MARKOWITZ, S. Exposição múltipla a agrotóxicos e efeitos à saúde: estudo transversal em amostra de 102 trabalhadores rurais, Nova Friburgo, RJ. Ciência \& Saúde Coletiva, v.12, p.115-130, 2007. DOI: http://doi.org/10.1590/S1413$\underline{81232007000100015}$

ATLASTI. The Qualitative Data Analysis \& Research Software. Boston: ATLASTI, 2019.

BARBOSA, L. G.; ALVES, M. A. S.; GRELLE, C. E. V.. Actions against sustainability: Dismantling of the environmental policies in Brazil. Land Use Policy, In press, 2021. DOI: http://doi.org/10.1016/j.landusepol.2021.105384

BARDIN, L.. Análise de conteúdo. São Paulo: Edições 70, 2010.

BEDOR, C. N. G.; RAMOS, L. O.; PEREIRA, P. J.; RÊGO, M. A. V.; PAVÃO, A. C.; AUGUSTO, L. G. D. S.. Vulnerabilidades e situações de riscos relacionados ao uso de agrotóxicos na fruticultura irrigada. Revista Brasileira de Epidemiologia, v.12, n.1, p.39-49, 2009. DOI: http://doi.org/10.1590/S1415790X2009000100005

BOCHNER, R.. Perfil das intoxicações em adolescentes no Brasil no período de 1999 a 2001. Cadernos de Saúde Pública, v.22, n.3, p.587-595, 2006. DOI: http://doi.org/10.1590/S0102-311X2006000300014
CARNEIRO, F. F.; AUGUSTO, L. G. D. S.; RIGOTTO, R. M.; FRIEDRICH, K.; BÚRIGO, A. C.. Dossiê Abrasco: um alerta sobre os impactos dos agrotóxicos na saúde. São Paulo: Expressão Popular, 2015.

CARSON, R.. Silent Spring (1962). Boston: Mariner Books, 2002.

CARVALHO, M. M. X.; NODARI, E. S.; NODARI, R. O.. "Defensivos" ou "agrotóxicos"? História do uso e da percepção dos agrotóxicos no estado de Santa Catarina, Brasil, 1950-2002. História, Ciências, Saúde-Manguinhos, v.24, n.1, p.75-91, 2017. DOI: http://doi.org/10.1590/s010459702017000100002

CASSAL, V. B.; AZEVEDO, L. F.; FERREIRA, R. P.; SILVA, D. G.; SIMÃO, R. S.. Agrotóxicos: uma revisão de suas consequências para a saúde pública. Revista Eletrônica em Gestão, Educação e Tecnologia Ambiental, v.18, n.1, p.437445, 2014. DOI: http://doi.org/10.5902/2236117012498

GASQUES, J. G.; REZENDE, G. C. D.; VERDE, C. M. V.; SALERMO, M. S.; CONCEIÇÃO, J. C. P. R.; CARVALHO, J. C. D. S.. Desempenho e crescimento do agronegócio no Brasil. Rio de Janeiro: IPEA, 2004.

GOGER, B.; KUNERT, O.; SEGER, C.; RINELLI, R.; WINTERSTEIGER, R.. Quantification of phenylurea pesticides by HPLC/ECD and photolysis. Electroanalysis: An International Journal Devoted to Fundamental and Practical Aspects of Electroanalysis, v.13, n.16, p.1335-1341, 2001. DOI: http://doi.org/10.1002/15214109(200111)13:16<1335::AID-ELAN1335>3.0.CO;2-W

HANNIGAN, J.. Sociologia Ambiental: A formação de uma perspectiva social. Lisboa: Instituto Piaget, 1995.

IBGE. Pesquisa Nacional por Amostra de Domicílios Contínua. Acesso à Internet e à Televisão e Posse de Telefone Móvel Celular para Uso Pessoal 2017. 2017.

MACHADO, P.. Um avião contorna o pé de Jatobá e uma nuvem de agrotóxico contorna a cidade. Brasília: Agência Nacional de Vigilância Sanitária, 2008. 
MELO, C. A. D.; MEDEIROS, W. N.; TUFFI SANTOS, L. D.; FERREIRA, F. A.; FERREIRA, G. L.; PAES, F. A. S. V.; REIS, M. R. Residual effect of sulfentrazone, isoxaflutole and oxyfluorfen in three soils. Planta daninha, v.28, n.4, p.835-842, 2010. DOI: http://doi.org/10.1590/S0100-83582010000400017

MILLER, G. T.; SPOOLMAN, S. R.. Environmental Science. 15 ed. Cengage Learning, 2015.

MOURA, J. T. V.; ROZENDO, C.; OLIVEIRA, M. V.. Movimento e contramovimento e as configurações do campo político em torno da utilização dos agrotóxicos no Brasil.

Desenvolvimento e Meio Ambiente, v.54, p.560-609, 2020. DOI: http://doi.org/10.5380/dma.v54i0.75103

OLIVEIRA, M. F.; BRIGHENTI, A. M.. Comportamento dos herbicidas no ambiente. In: OLIVEIRA JÚNIOR, R. S.; CONSTANTIN, J.; INOUE, M. H.. Biologia e manejo de plantas daninhas. Curitiba: Omnipax, 2011.

OLIVEIRA-SILVA, J. J.; ALVES, S. R.; MEYER, A.; PEREZ, F.; SARCINELLI, P. D. N.; MATTOS, R. D. C. O.; MOREIRA, J. C.. Influência de fatores socioeconômicos na contaminação por agrotóxicos, Brasil. Revista de Saúde Pública, v.35, n.2, p.130-135, 2001. DOI: http://doi.org/10.1590/S0034$\underline{89102001000200005}$

PERES, F.; ROZEMBERG, B.; LUCCA, S. R.. Percepção de riscos no trabalho rural em uma região agrícola do Estado do Rio de Janeiro, Brasil: agrotóxicos, saúde e ambiente. Cadernos Saúde Pública, v.21, n.6, p.1836-1844, 2005. DOI: http://doi.org/10.1590/S0102-311X2005000600033

PETERSEN, P.. Um novo grito contra o silêncio. In: CARNEIRO, F. F.; AUGUSTO, L. G. D. S.; RIGOTTO, R. M.; FRIEDRICH, K.; BÚRIGO, A. C.. Dossiê Abrasco: Um alerta sobre os impactos dos agrotóxicos na saúde. São Paulo: Expressão Popular, 2015.

PORTO-GONÇALVES, C. W.. O Desafio ambiental: Os porquês da desordem mundial. Mestres explicam a globalização. Rio de Janeiro: Record, 2004.

SCHLEGEL, R.. Internauta brasileiro: perfil diferenciado, opiniões indiferenciadas. Revista Sociologia Política, v.17, n.34, p.137-157, 2009. DOI: http://doi.org/10.1590/S0104$\underline{44782009000300011}$

VEIGA, J. E.. Desenvolvimento sustentável: o desafio do século XXI. Rio de Janeiro: Garamond, 2010.

WALKER, C.. Ecotoxicology: effects of pollutants on the natural environment. CRC Press, 2014.

ZECHENDORF, B.. Sustainable development: how can biotechnology contribute? Trends. Biotechnology, v.17, n.6, p.219-225, 1999. DOI: http://doi.org/10.1016/S01677799(98)01297-9

A CBPC - Companhia Brasileira de Produção Científica (CNPJ: 11.221.422/0001-03) detém os direitos materiais desta publicação. Os direitos referem-se à publicação do trabalho em qualquer parte do mundo, incluindo os direitos às renovações, expansões e disseminações da contribuição, bem como outros direitos subsidiários. Todos os trabalhos publicados eletronicamente poderão posteriormente ser publicados em coletâneas impressas sob coordenação da Sustenere Publishing, da Companhia Brasileira de Produção Científica e seus parceiros autorizados. Os (as) autores (as) preservam os direitos autorais, mas não têm permissão para a publicação da contribuição em outro meio, impresso ou digital, em português ou em tradução. 